$$
\text { Corf-7109/3--1 }
$$

\title{
A Study of Polyether-Polyol- and Polyester- Polyol-Based Rigid Urethane Foam Systems
}

Kansas City Division

J. P. Madden, G. K. Baker, and C. H. Smith

BDX-613-531

Published September 1971

Replacement Copy Delivered December 1994

Approved for public release; distribution is unlimited

Prepared Under Contract Number DE-ACO4-76-DP00613 for the United States Department of Energy

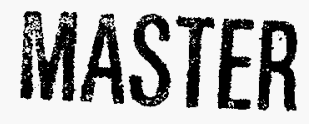

DISTRIBUTION OF THIS DOCUMENT IS UNLIMITED 


\section{DISCLAIMER}

This report was prepared as an account of work sponsored by an agency of the United States Government. Neither the United States Government nor any agency thereof, nor any of their employees, makes any warranty, express or implied, or assumes any legal liability or responsibility for the accuracy, completeness, or usefulness of any information, apparatus, product, or process disclosed, or represents that its use would not infringe privately owned rights. Reference herein to any specific commercial product, process, or service by trade names, trademark, manufacturer, or otherwise, does not necessarily constitute or imply its endorsement, recommendation, or favoring by the United States Government or any agency thereof. The views and opinions of authors expressed herein do not necessarily state or reflect those of the United States Government or any agency thereof.

Printed in the United States of America.

This report has been reproduced from the best available copy.

Available to DOE and DOE contractors from the Office of Scientific and Technical Information, P. O. Box 62, Oak Ridge, Tennessee 37831; prices available from (615) 576-8401, FTS 626-8401.

Available to the public from the National Technical Information Service, U. S. Department of Commerce, 5285 Port Royal Rd., Springfield, Virginia 22161.

Copyright $\odot 1994$ by AlliedSignal Inc. The Government is granted for itself and others acting on its behalf a paid-up, nonexclusive, irrevocable worldwide license in this data to reproduce, prepare derivative works, and perform publicly and display publicly.

A prime contractor with the United States Department of Energy under Contract Number DE-ACO4-76-DP00613.
AlliedSignal Inc. Kansas City Division P. O. Box 419159 Kansas City, Missouri 64141-6159 


\section{DISCLAIMER}

Portions of this document may be illegible in electronic image products. Images are produced from the best available original document. 
BDX-613-531

Distribution Category UC-701

Approved for public release; distribution is unlimited.

\section{A Study of Polyether-Polyol- and Polyester- \\ Polyol-Based Rigid Urethane Foam Systems}

J. P. Madden, G. K. Baker, and C. H. Smith

Published September 1971

Replacement Copy Delivered December 1994

Paper submitted to 162 nd National Meeting, American Chemical Society September 1971

Washington, D. C. 


\author{
A STUDY OF POLYETHER-POLYOL - AND POLYESTER- \\ POLYOL-BASED RIGID URETHANE FOAM SYSTEMS \\ by \\ J. P. Madden, G. K. Baker and C. H. Smith \\ Bendix Corporation, Kansas City Division \\ Materials Engineering \\ Post Office Box 1159 \\ Kansas City, Missouri 64141
}

\title{
INTRODUCTION
}

For the past 10 years polyurethane polymers have been one of the fastest growing segments of the plastics industry. Over 900 million pounds of polyurethanes were used in 1970 . Approximately 30 percent of this amount was consumed in the form of rigid urethane foam products (1).

Initially, polyester polyols were employed in both rigid and flexible foam formulations. In 1957, however, polyfunctional polyether polyols were introduced for use in urethane foam systems. Even though the development of rigid polyether foams was considerably slower than that of the flexible polyether foams, significant strides have been made in this field, and rigid polyether foams currently dominate the rigid urethane foam market.

Although some studies have been made to compare the properties of polyester- and polyether-based urethane elastomers, the literature contains only a limited amount of information on this subject, particularly as it pertains to rigid urethane foams $(2,3)$. Several authors have indicated that the properties of the two foam systems are comparable; however, very little data are available to substantiate these claims $(4,5,6,7$, and 8$)$.

This study undertakes a comparison of the properties of rigid urethane foams based on both a polyester polyol and polyether polyol of the same hydroxyl number prepared from alpha methylglucoside. This comparison of ester and ether polyols in urethane foams is closer than in previous studies because: (1) both types of polyols are based on alpha methylglucoside; (2) they both have the same hydroxyl number and functionality; and (3) the rigid foams in which they are used have been formulated to have essentially the same crosslink density.

Several physical and thermal properties of the foam systems were determined. A discussion of test results as they relate to the presence of the ester and ether linkages in the polyols is presented. 


\section{MATERIALS DESCRIPTION}

\section{Polymeric Components}

The alpha methylglucoside polyester polyol was prepared by reacting alpha methylglucoside (AMG) with epsilon-caprolactone to provide a tetrafunctional resin having both primary and secondary hydroxyl groups. This type of reaction is described in detail elsewhere and shall not be repeated here (9).

Two commercial polyether polyols, both polyoxypropylated alpha methylglucoside, were used interchangeably in this study. To obtain a polyether polyol which had the same hydroxyl number as the polyester polyol, it was necessary to blend two resins of different hydroxyl numbers. Initially, the polyether polyol used in this work was a blend of 49 percent Poly-G 375 (hydroxyl number 374) and 51 percent Poly-G 560 (hydroxyl number 571), both produced by Olin Chemicals. The other AMG polyether polyol blend consisted of 85 percent MEG 500 (hydroxyl number 482) and 15 percent MEG 300 (hydroxyl number 405), both produced by Corn Products Corporation. Since no significant differences in the properties evaluated in this study were observed between the two polyether polyol blends, no further distinction between the two polyol blends will be made.

The isocyanate components were derived from both toluene diisocyanate (TDI) and polydiphenylmethane diisocyanate (PMDI). Isocyanate prepolymers were prepared from both the AMG polyester and polyether polyols using $80 / 20$ toluene diisocyanate. PMDI-type prepolymers of the two polyols were also prepared.

\section{Foam Formulations}

Rigid urethane foam systems were formulated from the two types of polyols using both a TDI prepolymer and a PMDI prepolymer. The investigation employed carbon-dioxide-blown formulations having free-rise densities of approximately 6 pounds per cubic foot. An isocyanate index of 1.05

(5 percent excess) was used for the TDI foams and an index of 1.20 (20 percent excess) was used for the PMDI materials.

To obtain a direct comparison of rigid urethane foams based on polyesters versus those based on polyethers, the chemical parameters of the foam formulations were kept essentially identical. Both polyols had a hydroxyl number of 470 and a functionality of 4 . Furthermore, as shown in Table I, the concentrations of water and silicone cell stablizer used in each foam were the same. The concentration of tertiary amine used to catalyze the TDI foams was necessarily less than that used in the case of the PMDI foams. The variation in the quantity of isocyanate prepolymer used in the foam formulations, listed in Table $\mathrm{I}$, is due to small differences in the amine equivalents of the prepolymers. These differences are considered insignificant. 
Foam Samples

Test blocks were prepared from the four foam systems by molding the foams in 6 - by 6 - by 1 -inch metal molds to a density of $15 \pm 0.5$ pounds per cubic foot. The direction of foam rise was in the 6-inch direction. A fluorocarbon mold release was used to facilitate the release of the cured foam block from the mold.

The foam blocks were produced by mixing the $\mathrm{R}$ and $\mathrm{T}$ components for 1 to 3 minutes, using a Conn-type mixing impeller fitted to a high speed airdriven stirrer. The required amount of the foaming mixture was then weighed into the preheated mold to arrive at the desired density. The filled mold was allowed to remain at room temperature for 20 to 30 minutes and then the foam was cured for 8 hours at $325^{\circ} \mathrm{F}$.

EXPERIMENTAL

\section{Compressive Strength}

The compressive strength tests were conducted in accordance with ASTM Method D 695-54 over a temperature range of $-325^{\circ} \mathrm{F}$ to $+275^{\circ} \mathrm{F}$ for the TDI foams and from $-325^{\circ} \mathrm{F}$ to $+400^{\circ} \mathrm{F}$ for the PMDI foams. The test specimens were 1.129-inch-diameter by 1.00 -inch-high cylinders cut from the 6 - by 6 - by 1 -inch test blocks. This provided test specimens having a 1-squareinch test surface area and molded skins on the two test faces. The specimens were conditioned for at least 2 hours at the test temperature prior to testing and were compressed perpendicular to foam rise. A loading rate of 0.05 inch per minute was used and five determinations were made at each test temperature.

\section{Rise-Rate Determinations}

The rate of rise of the four systems as they foamed in open cups was determined with a Polytron Model 11 Rise-Rate Instrument. This instrument measures the reactivity characteristics of urethane foam materials by the rise of the foam under standardized conditions (10).

\section{Gel Permeation Chromatography}

A Waters Associates Gel Permeation Chromatograph, Model 200, was used to qualitatively determine the molecular weight distribution of the polyols. Samples were run in tetrahydrofuran at $27^{\circ} \mathrm{C}$, using columns having porosities of 60, 100, and 250 Angstroms. 
Isothermal Heat Aging

Foam samples (1.129-inch-diameter by 1.00 -inch-high cylinders) were placed in aluminum pans and weighed to the nearest $0.1 \mathrm{mg}$. The samples were then placed in a laboratory forced-air oven maintained at $347 \pm 3^{\circ} \mathrm{F}$. The weight loss was determined at regular intervals up to 28 days for the TDI foams and up to 62 days for the PMDI materials.

Thermogravimetric Analysis (TGA)

The TGA curves were obtained using a Du Pont Model 950 Thermogravimetric Analyzer. The powdered foam samples were heated in a nitrogen atmosphere from $25^{\circ} \mathrm{C}$ to $950^{\circ} \mathrm{C}\left(77^{\circ} \mathrm{F}\right.$ to $\left.1742^{\circ} \mathrm{F}\right)$ at a rate of $10^{\circ} \mathrm{C}\left(18^{\circ} \mathrm{F}\right)$ per minute.

Thermomechanical Analysis (TMA)

The softening points of the foam samples were determined using a Du Pont Model 941 Thermomechanical Analyzer. The samples were 0.5-inch in diameter and 0.075 -inch thick. The probe used had a flat tip $25 \mathrm{mils}$ in diameter and fitted with a 5 gram load. A heating rate of $5^{\circ} \mathrm{C}\left(9^{\circ} \mathrm{F}\right)$ per minute was employed for this test.

\section{RESULTS AND DISCUSSION}

It is interesting that with temperatures up to $300^{\circ} \mathrm{F}$, the compressive strengths of the foams prepared from the alpha methylglucoside polyether polyol are higher than those employing the polyester polyol as shown in Figure 1. Such a result is the reverse of the expected. It has generally been considered that, other factors being equal, the ester linkages provide a stronger intermolecular secondary bonding than ether linkages $(5,11)$. As a result, the compressive strength and apparent moduli of urethane foams based on polyester polyols are expected to be higher than comparable foams based on polyether polyols.

In this study, emphasis was placed on controlling the chemistry of the foam systems to provide as close a comparison as possible of rigid urethane foams prepared from polyesters and polyethers. Since the hydroxyl number and functionality were the same for both polyols, and since they were reacted with the same equivalents of isocyanate groups, the crosslink density of the two types of foam should be the same. Even the amount of water used in the formulations was held constant. This was done in an attempt to assure that the amount of urea formation from the reaction of water with the isocyanates would be the same in each foam prepared. 
An experimental comparison of the crosslink densities of the cured foams used in this work was made by measuring the swelling which occurred in foam samples immersed in different solvents. The extent of swelling varied depending upon the solvent. Although the ether based foams swelled at a faster rate, the equilibrium swelling values of both the ether and ester foams were the same for a given solvent. These results indicate that the intent to prepare foams that have the same crosslink densities is substantiated.

There are two chemical aspects of the ester and ether foams that are not directly comparable: the polyether polyol consists entirely of secondary hydroxyl groups; the polyester polyol is a mixture of primary and secondary hydroxyl groups. The amount of each type of hydroxyl groups in the polyester polyol is undetermined, but it can be estimated that there are slightly more primary hydroxyls than secondary. This is based on the most likely reactions which are expected to occur in the synthesis of the AMG polyester polyol, as well as on experimental evidence obtained from gel permeation chromatography and discussed in detail later in this paper.

Since primary hydroxyls react at a faster rate with isocyanates than with secondary hydroxyls (5), it was expected that foams made with the polyester polyol would blow and then gel at a faster rate than the polyether polyol. The rise-rate characteristics, summarized in Table II, show this to be true. To compensate for the difference in reactivity of polyester and polyether polyols with isocyanates, the foams were cured at $325^{\circ} \mathrm{F}$ for 8 hours. It was reasoned that such a rigorous cure would drive even the more lethargic reactions to completion.

The second chemical factor which could not be held constant in this study was the relative numbers of ether groups and ester groups present in the foams. For example, a polyether synthesized from AMG and propylene oxide having a hydroxyl number of 470 contains an average of 4.5 ether groups per molecule. A polyester polyol of 470 hydroxyl number synthesized from AMG and epsilon-caprolactone has an average of 2.5 ester groups per molecule.

Analysis of these polyols by gel permeation chromatography (GPC), illustrated in Figure 2, shows that the molecular weight distribution of the polyether is much narrower than that of the polyester. From Figure 2, it can be estimated that the polyether is nearly an equivalent mixture of molecules containing four and five propylene oxide units per AMG molecule. In the case of the polyester polyol, the peak designated $A$ in Figure 2 is due to a small amount of unreacted AMG. Peak $B$ is the reaction product of one molecule of AMG and one molecule of epsilon-caprolactone (ECL). Peaks $C$, D, and $E$ are due to the products of one molecule of AMG and two, three, and four molecules of ECL, respectively. 
One might argue that the higher compressive strengths exhibited by the polyether-polyol-based foams are due to the greater extent of hydrogen bonding present in these materials since the polyether polyols have nearly twice as many ether groups as the polyester polyol has ester groups. It is noted, however, that the number of oxygen atoms available for hydrogen bonding in foams made from the polyester is slightly greater than in foams made from the polyether. Furthermore, the polar carbonyl group in the ester may allow additional secondary intermolecular bonding that the ether groups cannot provide. In other words, this suggests that the contribution to the compressive strength from the secondary bonding should be greater in the case of the ester-urethane foams used in this study than the ether urethane foams. Yet, the compressive strength results showed the ether based foams to be stronger.

Assuming that the only significant difference in the two types of foams examined in this study is the presence of ester groups in one case and ether groups in the other, it can be concluded that the ether based foams have stronger secondary bonding than the ester foams.

This conclusion supports a similar conclusion made by Tanaka, Yokoyama, and Kaku (12). They performed infrared analyses on urethane elastomers prepared from both polyesters and polyethers. Their infrared analyses showed that polyether-urethane NH groups in elastomers are more readily hydrogen bonded than the polyester-urethane types.

The results of the isothermal heat aging study of the four foam systems heated at $347^{\circ} \mathrm{F}\left(175^{\circ} \mathrm{C}\right)$ in air are shown in Figure 3. The most thermally stable foam is the ester/PMDI system. The slope of the curve of percent weight loss versus time for the ether/PMDI system is about 1.3 times greater than the ester/PMDI system. The slope of the curves for the ester/TDI and the ether/TDI systems are 1.9 and 2.1 times greater than the ester/PMDI system, respectively. Therefore, the ester based foams exhibit slightly better thermal stability than the ether foams. At this temperature, however, the major factor influencing thermal stability in these urethane foams is the choice of isocyanate. Since the samples were heated in an air atmosphere, the data indicate the comparative oxidative stability of these foams.

Thermalgravimetric analyses of the four foam systems were carried out in a nitrogen atmosphere to observe degradation due to thermal rupture of chemical bonds. Figure 4 shows the TGA curves of the four systems, and data from selected portions of these curves are tabulated in Table III for comparison. The PMDI foams both remained stable to higher temperatures than the TDI foams. The onset of major degradation of both PMDI foams occurs at $270^{\circ} \mathrm{C}$ which is $60^{\circ} \mathrm{C}$ higher than the ester/TDI foam and $50^{\circ} \mathrm{C}$ higher than the ether/TDI foam. 
As the foams are exposed to higher temperatures, the weight loss of the ester/PMDI foam is the least of the four systems. This indicates that the rate of decomposition of the ester/PMDI is the lowest. At $350^{\circ} \mathrm{C}$, for example, the ester/PMDI foam has lost only 33 percent of its original weight compared to 45 percent weight loss for the ether/PMDI system and 66 percent and 94 percent weight loss for the ester/TDI and ether/TDI system foams, respectively.

Considering the temperature of major decomposition as the criterion for thermal stability, both the ester/PMDI and ether/PMDI have about the same thermal stability and are significantly more stable than the TDI foams. The ester/PMDI foam, however, exhibits the lowest rate of decomposition. This is consistent with the results of the isothermal heat aging tests. It is also consistent with the compressive data which shows that the decrease in compressive strength of the ester-based foams as a function of test temperature is less than in the case of the ether-based foams.

Thermalmechanical analysis (TMA) offers another method for evaluating thermal stability. In this study, the penetration of a flat probe $10.025-$ inch diameter) into the foam specimen was measured as the specimen was heated. The probe applied a constant load of about 20 psi. The TMA curves, Figure 5, show that the ester foams have softening temperatures of about $20^{\circ} \mathrm{C}$ higher than ether foams and the PMDI foams have higher softening temperatures than TDI foams. - The softening temperatures of the four foam systems are listed in Table IV. It should be noted that these temperatures represent the upper limits of thermal stability of these foams from the standpoint of utility in load-bearing applications.

Penetration of all four foams occurred at a temperature well below the degradation temperature as determined by TGA. Since these foams are highly crosslinked, true melting cannot occur. Therefore, the observed penetration must be due to some segmental motion of the polymer chains between crosslinks. In the case of the TDI foams, a bimodel penetration is shown which indicates that two distinct transitions occur within these foams (Figure 5). The first inflection in probe displacement for the ether/TDI foam is more definite than that of the ester/TDI foam, but is indeed real as was shown by repeated runs.

\section{CONCLUSIONS}

In summary, the study shows that rigid urethane foams made from ethers have higher compressive strengths, from $-320^{\circ} \mathrm{F}$ up to about $+300^{\circ} \mathrm{F}$, than comparable ester foams. Presumably, this difference in load-bearing properties can be attributed to stronger secondary bonding in ethers since the primary bonding in both foams was equivalent. In comparing the stability of these foams, from the standpoint of oxidative stability, thermal decomposition, and thermalmechanical behavior, the ester foams are more thermally stable than the ether foams. 


\section{ACKNOWLEDGEMENTS}

The authors wish to thank F. N. Larsen for his thermal analysis and interpretation, D. R. Ansley for preparing the test specimens, and the Bendix Corporation's Kansas City Division for allowing the presentation of this paper.

\section{REFERENCES}

1. A. S. Wood, Modern Plastics, 47, No. 11, 68 (1970).

2. A. Singh, L. Weissbein, and J. C. Mollica, Rubber Age, 98, No. 12 77 (1966).

3. P. C. Colodny and A. V. Tobolsky, Journal of the American Chemical Society, $\underline{79}, 4320$ (1957).

4. R. H. Stengard, Section IX, "Rigid Urethane Foams", in Handbook of Foamed Plastics, Ed. by R. J. Bender, Lake Publishing Corporation, Libertyville, Illinois, 125 (1965).

5. J. H. Sanders and K. C. Frisch, Polyurethanes - Chemistry and Technology, Interscience Publishers, New York, Part II, 199, (1964).

6. J. E. Wilson, Modern Plastics, 36, No. 9, 151 (1959).

7. J. E. Wilson and R. H. Fowler, Science, 128, 1343 (1958).

8. J. E. Wilson, H. M. Truax and M. A. Dunn, Journal of Applied Polymer Science 3, No. 9, 343 (1960).

9. C. H. Smith, Industrial and Engineering Chemistry, Product Research and Development 2,27 (1963).

10. R. Jennings, Journal of Cellular Plastics, 5, No. 3, 159 (1969).

11. R. E. Bolin, J. F. Szabat, R. J. Cote, Elaine Peters, P. G. Gemeinhardt, A. S. Morecroft, E. E. Hardy, and J. H. Saunders, Journal of Chemical and Engineering Data, 4, 261 (1959).

12. T. Tanaka, T. Yokoyama, and K. Kaku, Memoirs of the Faculty of Science, Kyushu University, 23, No. 2, 113 (1963). 
TABLE I

Formulation of the Foam Systems

\begin{tabular}{|c|c|c|c|c|}
\hline \multirow[b]{2}{*}{ COMPONENT } & \multicolumn{4}{|c|}{ COMPOSITION, PARTS BY WEIGHT. } \\
\hline & $\begin{array}{c}\text { SYSTEM } \\
\text { NO. } 1\end{array}$ & $\begin{array}{l}\text { SYSTEM } \\
\text { NO.2 }\end{array}$ & $\begin{array}{l}\text { SYSTEM } \\
\text { NO.3 }\end{array}$ & $\begin{array}{l}\text { SYSTEM } \\
\text { NO.4 }\end{array}$ \\
\hline $\begin{array}{l}\text { R-Component } \\
\text { Polyester-Polyol a } \\
\text { (OH } 470) \\
\text { Polyether-Polyol b }\end{array}$ & 100 & 100 & 100 & 100 \\
\hline Water & 1.5 & 1.5 & 1.5 & 1.5 \\
\hline $\begin{array}{l}\text { Silicone Cell } \\
\text { Stabilizer }\end{array}$ & 0.3 & 0.3 & 0.3 & 0.3 \\
\hline Amine Catalyst & 0.5 & 1.8 & 0.5 & 1.8 \\
\hline $\begin{array}{l}\text { T-Component } \\
\text { TDI Prepolymer (AE 145) }\end{array}$ & 177.8 & & 181.1 & \\
\hline PMDI Prepolymer (AE 150) & & 172.1 & & 182.9 \\
\hline
\end{tabular}

apsilon-caprolactone/alpho-methylglucoside polyester

bolypropylene oxide/alpha-methylglucoside polyether

TABLE II

Rise-Rate Characteristics of

Polyester and Polyether Polyol Foam Systems

\begin{tabular}{|c|c|c|c|c|}
\hline \multirow{2}{*}{ RISERATE PROPERTY } & \multicolumn{2}{|c|}{ POLYESTER-POLYOL } & \multicolumn{2}{|c|}{ POLYETHER-POLYOL } \\
\hline & TDI & PMDI & TDI & PMDI \\
\hline $\begin{array}{l}\text { Initiation Time } \\
\text { ( } 2 \% \text { expansion), sec. }\end{array}$ & 105 & 75 & 105 & 75 \\
\hline $\begin{array}{l}\text { Rise Time }(95 \% \\
\text { exponsion), sec. }\end{array}$ & 405 & 180 & 525 & 285 \\
\hline $\begin{array}{l}\text { Time to Maximum } \\
\text { Velocity, sec. }\end{array}$ & 195 & 155 & 225 & 260 \\
\hline Maximum Velocity, in./min & 1.7 & 8.2 & 1.1 & 3.6 \\
\hline $\begin{array}{l}\text { Rise-Rate Constant, } \\
\text { in } . / \mathrm{min} / \mathrm{in} \text {. }\end{array}$ & 4.8 & 5.8 & 5.5 & 7.6 \\
\hline
\end{tabular}


TABLE IV

Summary of TMA Data for

Polyester and Polyether Polyol Foam Systems

FOAM SYSTEM

Ether/TDI

Ester/TDI

Ether/PMDI

Ester/PMDI
INITIAL PENETRATION, ${ }^{\circ} \mathrm{C}$

160

180

180

200

\section{TABLE III}

Summary of TGA Data for

Polyester and Polyether Polyol Foam Systems

FOAM SYSTEM

Ether/TDI

Ester/TDI

Ether/PMDI

Ester/PMDI

\begin{tabular}{l} 
ONSET OF MAJOR \\
DEGRADATION, ${ }^{\circ} \mathrm{C}$ \\
\hline
\end{tabular}

240

230

290

290
PERCENT OF

WEIGHT LOSS

AT $350^{\circ} \mathrm{C}$

94

66

45

33 


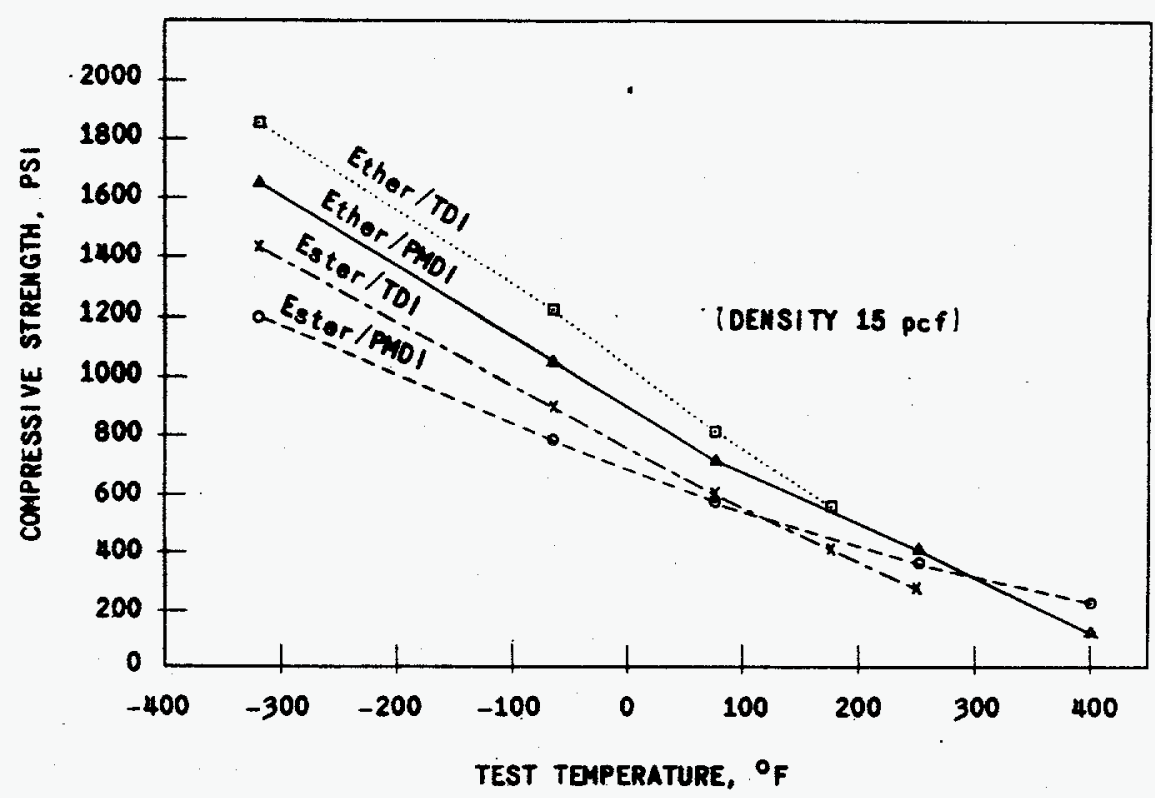

FIGURE I Compressive Strength Versus Temperature

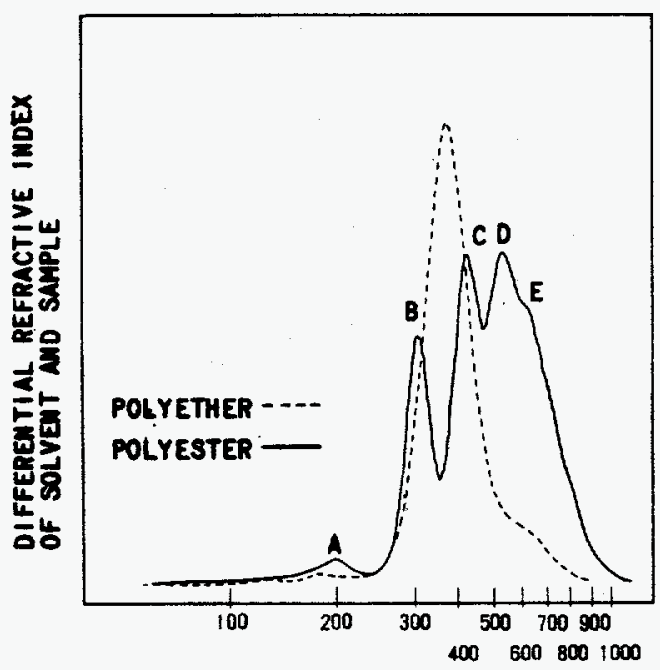

MOLECULAR WEIGHT, G/MOLE

FIGURE 2 Gel Permeation Chromatograph

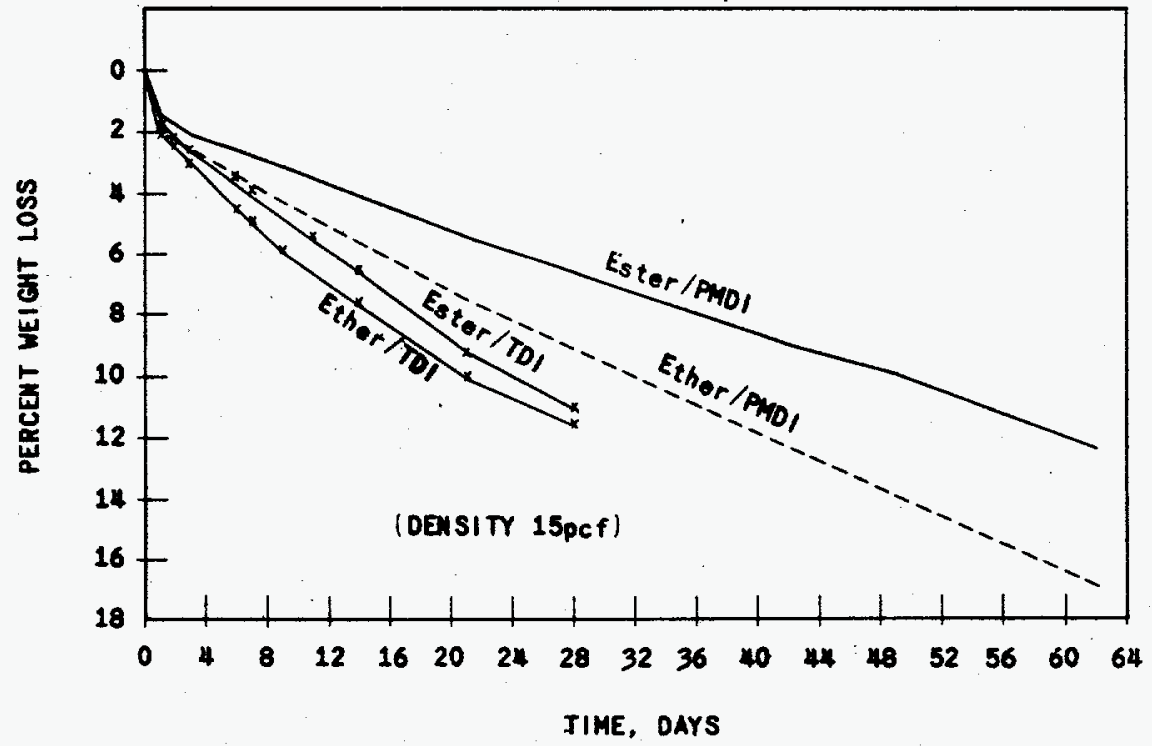

FIGURE 3 Heat Aging Curves 


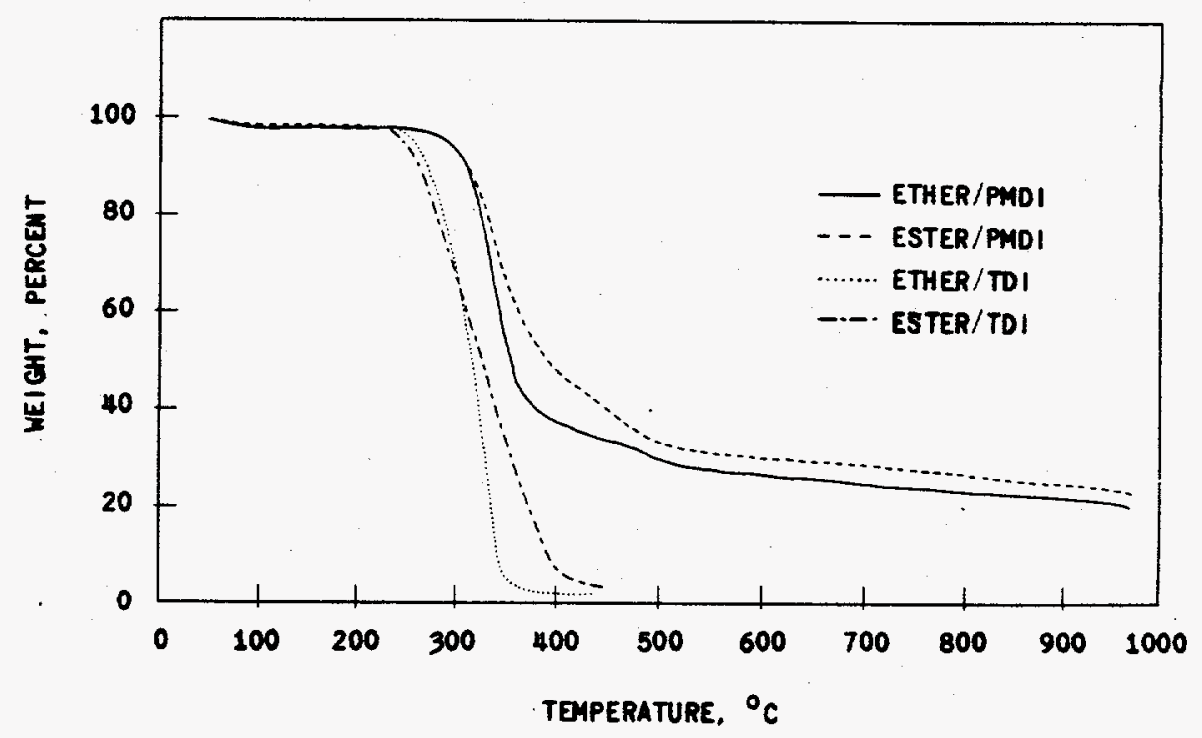

FIGURE 4 Thermogravimetric Analysis (TGA)

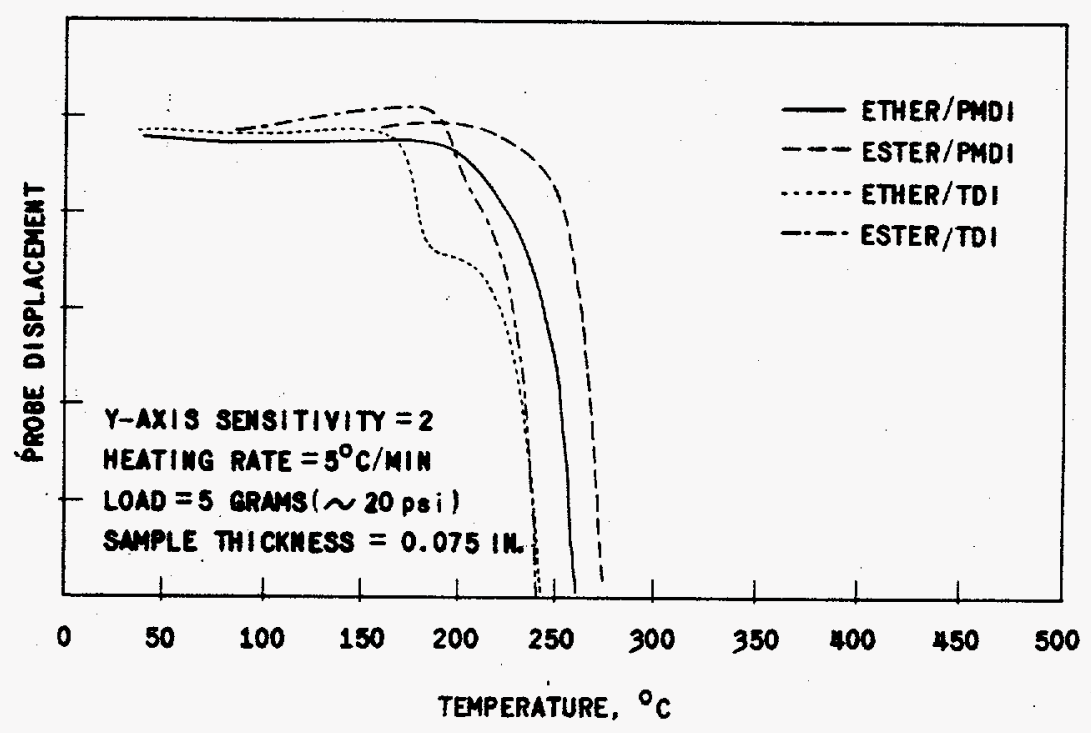

FIGURE 5 Thermomechanical Penetration Analysis (TMA) 